\title{
Anti-fibrotic action of pirfenidone in Dupuytren's disease-derived fibroblasts
}

\author{
Chaoming Zhou', Fang Liu', Phillip H. Gallo', Mark E. Baratz², Sandeep Kathjü ${ }^{3,4}$ and Latha Satish 3,4*
}

\begin{abstract}
Background: Dupuytren's disease (DD) is a complex fibro-proliferative disorder of the hand that is often progressive and eventually can cause contractures of the affected fingers. Transforming growth factor beta (TGF- $\beta_{1}$ ) has been implicated as a key stimulator of myofibroblast activity and fascial contraction in DD. Pirfenidone (PFD) is an active small molecule shown to inhibit TGF- $\beta_{1}$-mediated action in other fibrotic disorders. This study investigates the efficacy of PFD in vitro in inhibiting TGF- $\beta_{1}$-mediated cellular functions leading to Dupuytren's fibrosis.

Methods: Fibroblasts harvested from (DD) and carpal tunnel (CT)- tissues were treated with or without TGF- $\beta_{1}$ and/ or PFD and were subjected to cell migration, cell proliferation and cell contraction assays. ELISA; western blots and real time RT-PCR assays were performed to determine the levels of fibronectin; p-Smad2/Smad3; alpha-smooth muscle actin (a-SMA), a2 chain of type I collagen and a1 chain of type III collagen respectively.

Results: Our results show that PFD effectively inhibits TGF- $\beta_{1}$-induced cell migration, proliferation and cell contractile properties of both CT- and DD-derived fibroblasts. TGF- $\beta_{1}$ _induced a-SMA mRNA and protein levels were inhibited at the higher concentration of PFD $(800 \mu \mathrm{g} / \mathrm{ml})$. Interestingly, TGF- $\beta_{1}$ induction of type I and type III collagens and fibronectin was inhibited by PFD in both CT- and DD- derived fibroblasts, but the effect was more prominent in DD cells. PFD down-regulated TGF- $\beta_{1}$-induced phosphorylation of Smad2/Smad3, a key factor in the TGF- $\beta_{1}$ signaling pathway.

Conclusion: Taken together these results suggest the PFD can potentially prevent TGF- $\beta_{1}$ induced fibroblast to myofibroblast transformation and inhibit ECM production mainly Type I- and Type III- collagen and fibronectin in DD-derived fibroblasts. Further in-vivo studies with PFD may lead to a novel therapeutic application in preventing the progression or recurrence of Dupuytren's disease.
\end{abstract}

Keywords: Dupuytren's contracture, Palmar fascia fibrosis, Carpal tunnel, Collagen, Alpha-SMA, Smad2/Smad3, Cell migration, Cell contraction

\section{Background}

Dupuytren's disease (DD) is a common fibroproliferative disorder of the hand that is often progressive and eventually can cause contractures of the affected fingers [1]. $\mathrm{DD}$ is considered to be caused by a defect in the process of wound healing or by an excessive or abnormal response to wounding [2]. DD is a multifactorial and complex disease, and has been reported to have an association with inherited genetic markers, alcohol and

\footnotetext{
*Correspondence: las238@pitt.edu

${ }^{3}$ McGowan Institute for Regenerative Medicine, University of Pittsburgh,

Pittsburgh, PA, USA

${ }^{4}$ Department of Plastic Surgery, University of Pittsburgh, 3550 Terrace Street,

Scaife Hall, S685.2, Pittsburgh, PA 15261, USA

Full list of author information is available at the end of the article
}

tobacco use [3], and different systemic diseases such as diabetes [4], and epilepsy [5]. The disease usually begins with the formation of highly vascularized nodules and over the years develops into collagenous rich cords. Myofibroblasts that share characteristic features of both fibroblasts and smooth muscle cells have been shown to play a critical role in tissue contraction of DD [6, 7]. Acting along with this cell population are several growth factors and cytokines that are implicated in the progression of the disease $[2,8]$.

Dupuytren's disease commonly affects populations of northern European descent, with the prevalence of DD in the general population of Western countries ranging from 0.6 to $31.6 \%$ [9]. The prevalence rate in the United 
States is reported to be $>7 \%$ [10]. In the USA, disability and treatments for DD account for significant losses to the economy and substantial direct and indirect costs [11]. At present there is no cure for DD. The cornerstone of treatment has, historically, been surgical excision of involved palmar fascia release of diseased skin. More recently percutaneous needle fasciotomy and collagenase injections in the cords, is practiced as an alternative to more invasive surgery $[12,13]$. Recurrence rates seem to be higher with the less invasive techniques and these strategies do have their own unique complications $[14,15]$. Recurrence of DD overall ranges from 8 to $66 \%$ depending on the severity and treatment of disease [16], underscoring the importance of additional research on the causes and factors related to recurrence.

Among all the growth factors that have been studied in $\mathrm{DD}$, transforming growth factor $-\beta$ (TGF- $\beta$ ) is shown to play a major role in the pathophysiology of DD $[17,18]$. In fibroblasts derived from Dupuytren's affected and unaffected tissue, TGF- $\beta$ can upregulate $\alpha$-SMA and is recognized to be the key inducer in differentiating a quiescent fibroblast to a contracting myofibroblast [18]. The inhibition or reversion of the myofibroblast phenotype to normal may mitigate disease progression and severity. Previous studies from our laboratory have shown that increasing cyclic AMP (cAMP) levels via forskolin (an adenylate cyclase (AC) activator) has potential to inhibit TGF- $\beta$-induced myofibroblast formation and accumulation of ECM components in DD-derived fibroblasts [19]. Overproduction of cAMP that can provide a means to blunt fibrosis has also been shown in cardiac and pulmonary fibroblasts $[20,21]$. Clinical data about the usage of forskolin are not yet available as the risk-benefit ratio is not fully evaluated [22].

In the present study, we have chosen to investigate the action of pirfenidone (PFD; 5-methyl-1-phenyl-2(1H)pyridone) a small molecule well-documented for its antifibrotic and anti-inflammatory properties in a variety of pre-clinical and in vitro models in different organs, including fibrosis of the lung [23], kidney [24], heart [25], liver [26], and skin [27]. PFD has been shown to inhibit both production and activity of TGF- $\beta 1$, a cytokine that stimulates collagen synthesis and inhibits its degradation [28], and also to reduce the production of other fibrogenesis mediators, such as fibronectin and connective tissue growth factor (CTGF) $[29,30]$. The ability of PFD to combat the fibrosis seen in DD has not previously been reported. PFD is an FDA approved drug for the treatment of idiopathic pulmonary fibrosis in the United States, and thus represents an attractive potential therapy for Dupuytren's disease.

In this study we examine the ability of PFD to modulate TGF- $\beta_{1}$-mediated actions on the DD fibroblast's functional properties, namely cell proliferation, cell migration and cell contraction. In addition, we also examine the effect of PFD on the canonical signaling pathway known to mediate TGF- $\beta_{1}$ effects in other fibrotic systems.

\section{Methods \\ Cell culture}

Primary cultures of fibroblasts were isolated from freshly resected DD cord tissue and normal palmar fascia (CT cells) as previously described [31]. DD cord and CT fascial tissue samples were surgically resected at the Division of Upper Extremity Surgery, Department of Orthopaedic Surgery, Allegheny General Hospital, Pittsburgh, PA. All subjects signed the written informed consent forms, and the protocol was approved by the Allegheny-Singer Research Institute's Institutional Review Board (IRB protocol no. RC-4040). The study protocol strictly conformed to the ethical guidelines of the 1975 Declaration of Helsinki. Cells are maintained in alpha-MEM medium (Invitrogen ${ }^{\mathrm{Tn}}$, ThermoFisher Scientific, Pittsburgh, PA) with 10\% FBS and Penicillin/Streptomycin antibiotics (Gibco ${ }^{\circ}$, ThermoFisher Scientific) with $5 \% \mathrm{CO}_{2}$. Cells used for all experiments were within passages two to seven.

\section{Cell viability/proliferation}

CT- and DD-cord-derived fibroblasts $\left(5 \times 10^{4}\right)$ seeded on a 24 well plate were grown overnight in alpha-MEM medium containing 10\% FBS. Following day, cells were switched to alpha-MEM medium containing $0.1 \%$ dialyzed FBS for $24 \mathrm{~h}$ followed by treatment with different concentrations of PFD $(0,200,400$ and $800 \mu \mathrm{g} / \mathrm{mL})$ with or without $10 \mathrm{ng} / \mathrm{ml}$ TGF- $\beta 1$ in low-serum medium for additional $24 \mathrm{~h}$. After the incubation period, cells were photographed, and MTT assay was performed using the CellTiter $96^{\circ}$ Non-Radioactive Cell Proliferation Assay kit obtained from Promega Corporation (Madison, WI) [31]. Cells were replaced with fresh growth medium and dye solution and incubated at $37{ }^{\circ} \mathrm{C}$ for $2 \mathrm{~h}$. After adding solubilization/stop solution, cells were incubated for another $1.5 \mathrm{~h}$ at $37^{\circ} \mathrm{C}$. Results were obtained using a plate reader by measuring absorption at $570 \mathrm{~nm}$ of $100 \mu \mathrm{l}$ aliquots placed into a Corning 96 well flat transparent plate.

\section{Lactate Dehydrogenase (LDH) cytotoxicity assay}

$\mathrm{LDH}$ is a cytosolic enzyme that is not normally discharged outside of the cell, but is released into the cell culture medium upon damage to the cellular membrane. Measurement of extracellular LDH release into the culture medium can be used to assay cellular toxicity. CT- and DD-derived fibroblasts $\left(5 \times 10^{4}\right)$ were seeded in a 24 well plate and were grown overnight in alpha-MEM medium containing 10\% FBS. Following day, cells were switched to alpha-MEM medium containing $0.1 \%$ dialyzed FBS for $24 \mathrm{~h}$ followed by treatment with different concentrations of PFD $(0,200,400$ and $800 \mu \mathrm{g} / \mathrm{mL})$ in low-serum 
medium for an additional $24 \mathrm{~h}$. After $24 \mathrm{~h}$ of exposure, extracellular LDH activity was measured using the In Vitro Toxicology Assay Kit, Lactate Dehydrogenase-based (Sigma-Aldrich, St. Louis, MO) according to the manufacturer's instructions. The absorbance of LDH release (from medium) was separated and measured using a plate reader at a wavelength $490 \mathrm{~nm}$ (primary) and $690 \mathrm{~nm}$ (background) by aliquoting $30 \mu \mathrm{L}$ into a Corning 96 well flat transparent plate. LDH activity was expressed as fold change versus control samples after the background subtraction.

\section{Cell migration}

Cell migration assays were done using the Oris ${ }^{\mathrm{mm}}$ Cell Migration assay (Platypus Technologies, Fitchburg, WI) which offers an alternative to the "scratch" test which can vary between experiments and can disrupt extracellular matrix which is vital for cell migration. In brief, this procedure employs a stopper dissolvable biocompatible gel (BCG) to create the cell-free gap in the center of a well in a microplate. Cells seeded into each well are initially restricted from adhering to the center of each well creating a "detection zone". CT- and DD-cord derived fibroblasts were stained with $3 \mu \mathrm{M}$ CellTracker ${ }^{\mathrm{Ts}}$ Red CMTPX Dye (Molecular Probes ${ }^{\mathrm{Tm}}$, ThermoFisher Scientific) in alpha-MEM medium containing 10\% FBS for 30 min. Cells $\left(1 \times 10^{4}\right)$ were seeded into the wells containing Oris $^{\text {тा }}$ Cell Stoppers in Fibronectin Coated or Non-Coated 96- well plate (Platypus Technologies, Fitchburg, WI) and incubated overnight. Following day, the cell stoppers were removed carefully using the Stopper tool leaving the internal controls. Cells were quiesced in the medium containing $0.1 \%$ dialyzed FBS for $24 \mathrm{~h}$. Cells were treated with PFD $(800 \mu \mathrm{g} / \mathrm{mL})$ with or without $10 \mathrm{ng} / \mathrm{ml}$ TGF- $\beta_{1}$ in low-serum medium for additional $24 \mathrm{~h}$. The stoppers in the internal control well were removed just before imaging. The cell migration was assessed by a number of cells that enter the detection zone using NIH Image J 1.44p, available in the public domain at http://imagej.nih.go/ij.

\section{Stressed Fibroblast -Populated Collagen Lattice Assay (sFPCL)}

Cell contractility of the fibroblasts was tested using FPCL assay as previously described with slight modifications [32]. In brief, collagen lattices were prepared by mixing cell suspensions with a neutralized solution of type I collagen matrix (four parts rat tail collagen, one part neutralization solution; two parts $0.34 \mathrm{M} \mathrm{NaOH}: 3$ parts 10X Waymouth media). Cells were exposed to alpha-MEM medium containing 0.1\% dialyzed FBS $24 \mathrm{~h}$ prior to plating in 24-well plate. Each well in a 24-well culture dish contained $1 \times 10^{5}$ of CT- and DD-derived fibroblasts in $0.5 \mathrm{ml}$ of the collagen mixture along with or without PFD $(800 \mu \mathrm{g} / \mathrm{ml})$ and TGF- $\beta_{1}(10 \mathrm{ng} / \mathrm{ml})$. Following FPCL polymerization $\left(1 \mathrm{~h}, 37^{\circ} \mathrm{C}\right), 0.5 \mathrm{ml}$ of alpha-MEM medium containing 2\% FBS was added to the top of each lattice and incubated overnight. After $24 \mathrm{~h}$ incubation, the attached FPCLs were then manually released from the sides of the culture plates and digitally scanned every $24 \mathrm{~h}$ after release until day 6 . The area of the lattices was quantified using Adobe Photoshop and was plotted.

\section{Quantitative Real-time RT-PCR (qRT-PCR)}

Total RNA isolated (RNeasy Micro Kit, Qiagen Inc, Valencia, CA) from CT- and DD-derived fibroblasts treated and untreated with PFD $(800 \mu \mathrm{g} / \mathrm{ml})$ and TGF- $\beta_{1}$ (10 $\mathrm{ng} / \mathrm{ml}$ ) was subjected to real-time RT-PCR to determine the mRNA expression levels for $\alpha$-SMA (ACTA2), type I collagen (COL1A2), and type III collagen (COL3A1). Human GAPDH was used as an normal endogenous control. Real-time RT-PCR was performed using kits obtained from Applied Biosystems (Applied Biosystems ${ }^{\oplus}$, ThermoFisher Scientific) that utilize FAM $^{\mathrm{rm}}$ Taqman $^{\circ} \mathrm{MGB}$ probes and a Taqman ${ }^{\odot}$ Universal PCR Master Mix. $100 \mathrm{ng}$ of total RNA from samples were used for the reverse transcriptase (RT) reaction along with random primers (100 ng) and with M-MLV reverse transcriptase (Invitrogen). Taqman probes for above-noted gene products were purchased from Applied Biosystems. The remaining protocol parameters for subsequent real- time PCR was followed as described previously ${ }^{19}$. Applied Biosystems transcriptspecific assays used were COL1A2 (ID- Hs01028971_ml), COL3A1 (ID-Hs00943793), ACTA2 (ID-HS00426835_g1) and GAPDH (ID-Hs99999905_m1). Using the comparative critical cycle $(\mathrm{Ct})$ method the expression levels of the target genes were normalized to the GAPDH and the relative abundance was calculated. Data were analyzed using the 7900 HT SDS software version 2.2 .2 provided by Applied Biosystems.

\section{Western blotting}

CT- and DD-derived fibroblasts $\left(2 \times 10^{5}\right)$ were seeded in six well plates with growth medium containing $10 \%$ FBS overnight followed by exposing the cells in $0.1 \%$ dialyzed FBS-containing medium for $24 \mathrm{~h}$. Cells were treated with $800 \mu \mathrm{g} / \mathrm{ml}$ PFD with or without $10 \mathrm{ng} / \mathrm{ml}$ TGF- $\beta_{1}$ in low-serum medium for an additional $24 \mathrm{~h}$. Following the treatment cells were washed with ice-cold PBS once and then lysed in M-PER ${ }^{\mathrm{TM}}$ Mammalian Protein Extraction Reagent (ThermoFisher Scientific) with proteinase inhibitors (cOmplete ULTRA Tablets, Mini, EDTA-free) and Phosphostop purchased from Roche Diagnostics Corporation (Indianapolis, IN). Proteins were resolved by SDS-PAGE, and standard Western blotting procedure was applied. Primary antibodies used were: mouse monoclonal anti-Actin $\alpha$ Smooth Muscle 
Antibody (predicted and observed molecular weight is 42 kDa 1:5000; Sigma-Aldrich, St. Louis, MO), mouse monoclonal anti-GAPDH antibody, detects a band approximately at $\sim 36 \mathrm{kDa}$ and the predicted molecular weight is $40.2 \mathrm{kDa}$ (1:5000; Abcam, Cambridge, MA), phosphor-Smad2 (Ser465/467)/Smad3(Ser423/425)(D27F4) (1:1000) Rabbit mAb (1:1000) (Cell Signaling, Boston, MA). The predicted molecular weight for pSMAD2 is $60 \mathrm{KDa}$ and for pSMAD3 is 52KDa. The observed molecular weights approximate the predicted molecular weights.

Membranes were washed and then incubated for an hour in room temperature with IRDye $800 \mathrm{CW}$ Gt AntiRabbit IgG $(\mathrm{H}+\mathrm{L})$ antibody and IRDye 680LT Anti-Mouse IgG $(\mathrm{H}+\mathrm{L})$ antibody $(1: 15,000)$ (Li-COR Bioscience, Lincoln, NE). Infrared fluorescence was detected by the Odyssey $^{\circ}$ Imaging System (Li-COR Bioscience). The protein bands scanned were analyzed using $\mathrm{NIH}$ Image J 1.44p. The data obtained was normalized with GAPDH.

\section{Enzyme- Linked Immunosorbent Assay (ELISA)}

CT- and DD-derived fibroblasts $\left(1 \times 10^{4}\right)$ seeded in 96 well plates were grown in growth medium overnight, and cells were changed to medium containing $0.1 \%$ dialyzed FBS for $24 \mathrm{~h}$. Cells were treated with $800 \mu \mathrm{g} / \mathrm{mL}$ of PFD with or without $10 \mathrm{ng} / \mathrm{ml}$ TGF- $\beta_{1}$ in low-serum medium for another $24 \mathrm{~h}$. Following the treatment, secreted proteins in the growth medium were collected in the conditioned medium, which was centrifuged for $10 \mathrm{~min}$ to collect the supernatant. Fibronectin levels were analyzed in the supernatants using Human Fibronectin
SimpleStep ELISA Kit from Abcam according to the manufacturer's instructions.

\section{Results \\ Effect of PFD on the proliferative efficiency of CT- and DD-derived fibroblasts}

Various concentrations of PFD $(0,200,400,800 \mu \mathrm{g} / \mathrm{ml})$ were tested on CT- and DD-cord derived fibroblasts with or without the stimulation of TGF- $\beta_{1}$. A dosedependent effect on cell proliferative efficiency was seen in both CT-and DD-cord derived fibroblasts (Fig. 1a and b). A statistically significant inhibition of both basal and TGF- $\beta_{1}$ stimulated cell proliferation was observed at all the different concentrations, and highest inhibition was seen at $800 \mu \mathrm{g} / \mathrm{ml}$. In order to confirm that the reduction of cell proliferative efficiency observed was not due to cytotoxicity we performed LDH assay and determined that there was no cytotoxic effect observed $24 \mathrm{~h}$ after treating with different doses of PFD (Fig. 2). No change in cellular morphology (data not shown) was observed, confirming the non-toxic effect of PFD even at higher concentrations on both CT- and DD-cord derived fibroblasts. To determine the functional significance of inhibition of PFD on CT and DD-cord derived fibroblasts, $800 \mu \mathrm{g} / \mathrm{ml}$ of PFD was used for further experimentation.

\section{PFD significantly inhibits basal and growth factor-induced} cell migration on both $2 \mathrm{D}$ and $3 \mathrm{D}$ surfaces

It is still unclear what role migration of cells plays in the development of the diseased cord in DD disease, although given the severity of contractures that can form some migration of cells as well as cellular contraction

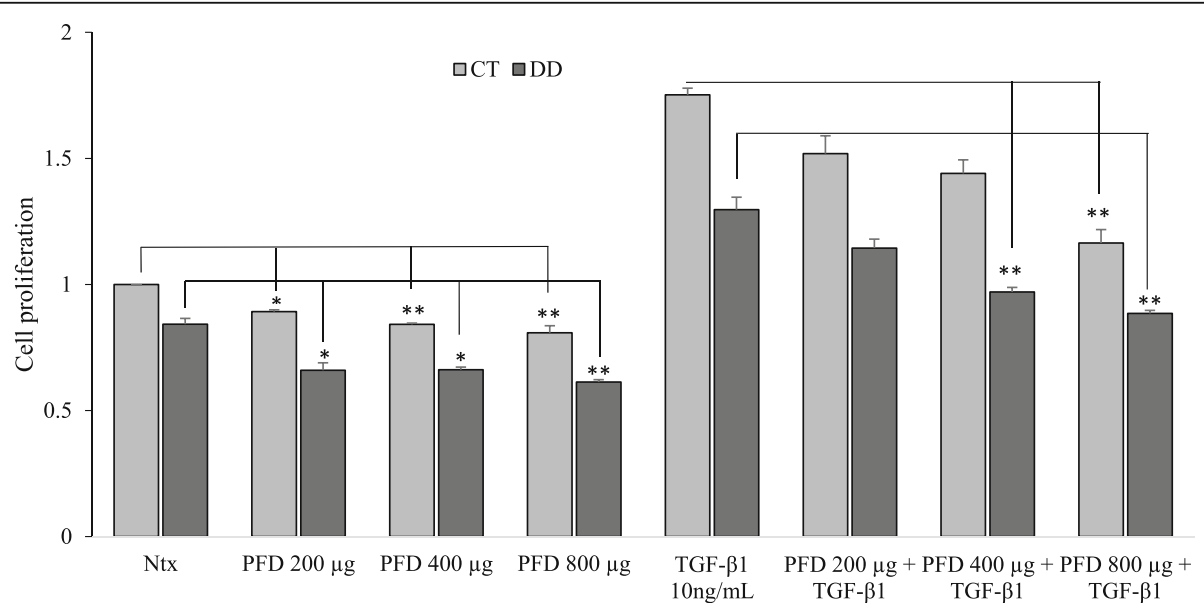

Fig. 1 Cell proliferative ability was diminished after the addition of Pirfenidone. (a) CT- and (b) DD-derived fibroblasts derived from four different patient samples ( $N=4 /$ group) were exposed to varying concentrations of PFD $(0,200,400,800 \mu \mathrm{g} / \mathrm{ml})$ and TGF- $\beta_{1}(10 \mathrm{ng} / \mathrm{ml})$. Cells were then subjected to MTT assay to determine the effect of PFD on basal and TGF- $\beta_{1}$-induced cell proliferation. Cell proliferation is displayed as absorbance values of untreated CT-derived fibroblasts normalized to 1 and compared with other treatments. Data are shown as mean \pm SEM of the averages of triplicate reads for each culture derived from the four different patient samples both for CT- and DD-derived fibroblasts. Statistical analysis was performed using one-way ANOVA. ${ }^{*} p<0.05 ;{ }^{* *} p<0.01$ 


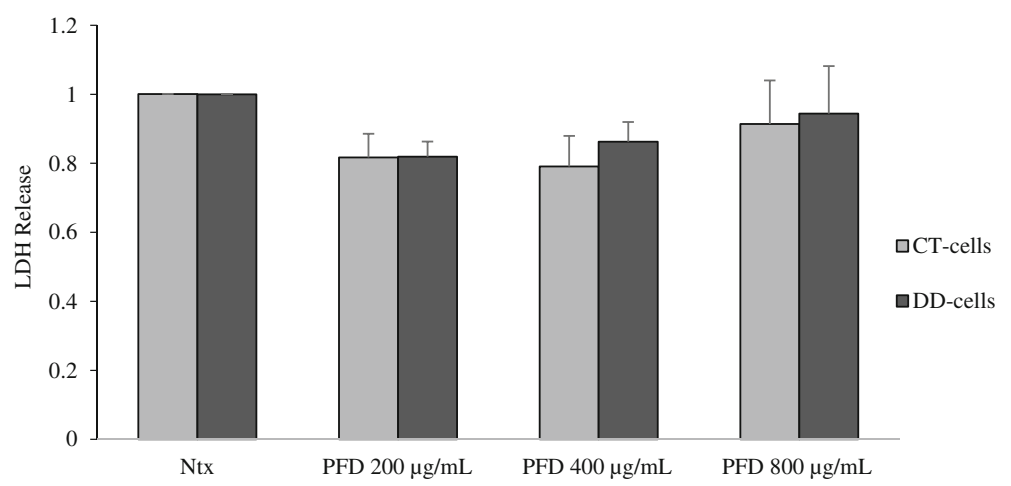

Fig. 2 Cell viability was not affected by the presence of Pirfenidone. CT- and DD-derived fibroblasts derived from three different patient samples ( $N=3$ /group) were incubated with different concentrations of PFD $(0,200,400,800 \mu \mathrm{g} / \mathrm{ml})$, and the extracellular LDH release into the culture medium was measured as described in Materials and Methods. Data are shown as mean \pm SEM of the averages of triplicate reads for each culture derived from the four different patient samples both for CT- and DD-derived fibroblasts. Ntx = no treatment (neither PFD nor TGF- $\beta_{1}$ added control). Statistical analysis was performed using one-way ANOVA. ${ }^{*} p<0.05 ;{ }^{* *} p<0.01$

seems likely. Our previous studies have shown that the basal cell migratory potential of DD cells was much higher than that of CT- derived fibroblasts (data not shown). In the present study, we investigated the effect of PFD $(800 \mu \mathrm{g} / \mathrm{ml})$ on basal and TGF- $\beta_{1}$-induced cell migration on fibronectin non-coated (2D) and coated surfaces (3D). No significant cell migratory stimulus was observed from the addition of TGF- $\beta_{1}$ in both CT-and DD-cord derived fibroblasts in both fibronectin noncoated (Fig. 3a \&b) and coated surface plates (Fig. 3c $\& d)$. Interestingly, a significant inhibition of basal cell migration was noted in both CT-and DD-cord derived fibroblasts in both $2 \mathrm{D}$ and $3 \mathrm{D}$ assays when the cells were treated with PFD. The addition of PFD to TGF- $\beta_{1}$-stimulated cells similarly reduced cell capacity to migrate.

\section{PFD inhibition of basal- and TGF- $\beta_{1}$ - induced cell contraction} is evident in both CT- and DD-cord derived fibroblasts

TGF- $\beta_{1}$ is a growth factor known to induce fibroblast contraction, and it is known to play a critical role in the development of Dupuytren's disease. Indeed, the deforming force of cellular contraction, on a tissue level, must play a critical role in the development of the extreme contractures that can develop. We determined that TGF- $\beta_{1}$ induced contraction of both CT-and DDderived fibroblasts, whereas addition of PFD abrogated both basal- and TGF- $\beta_{1}$-mediated- contraction (Fig. 4a, b \& c). Since $\alpha$-SMA is the major protein involved in the molecular generation of cellular contraction force, we questioned if the increase in $\alpha$-SMA levels engendered by TGF- $\beta_{1}$ can be reduced by the addition of PFD. We found that PFD substantially inhibited TGF- $\beta_{1}$ - induced $\alpha$-SMA at both mRNA (Fig. 5a \& b) and protein levels (Fig. 5c \& d) in both CT- and DD-derived fibroblasts. PFD by itself did not have any significant effect on $\alpha$-SMA mRNA or protein levels in both cell types. These results again strongly indicate that DD fibroblastic cells, in a manner similar to normal fibroblasts, are responsive to PFD action, highlighting the potential of the drug as a candidate to inhibit myofibroblast formation in DD, in turn likely reducing DD contractures.

PFD attenuates type I and type III collagen subunit mRNA expression in both CT- and DD-derived fibroblasts

Since increased collagen accumulation is the hallmark for fibrosis and the progression of Dupuytren's disease [33], our next goal was to investigate if PFD can inhibit collagen accumulation. Interestingly, we found that both basal expression and TGF- $\beta_{1}$ induction of type I $(\alpha-2$ chain; COL1A2) and type III collagen ( $\alpha-1$ chain; COL3A1) mRNA levels were significantly inhibited in both CT- and DD- derived fibroblasts by addition of PFD (Fig. 6a-d). PFD appears to more greatly inhibit collagen message in DD cells compared to CT cells. These fingings reiterate PFD as an attractive candidate to mitigate collagen accumulation (and therefore disease phenotype) in DD.

\section{PFD suppresses TGF- $\beta_{1}$ - induced fibronectin protein levels}

The palmar fascia fibrosis seen in DD is associated with excessive deposition of extracellular matrix (ECM) components including fibronectin [19]. DD tissues and cells have been reported to show increased expression of fibronectin type III extra-domain B (FN 1-ED-B) and "oncofetal" fibronectin levels [34, 35] which prompted us to determine if PFD can play a role in reducing fibronectin levels. We found that PFD $(800 \mu \mathrm{g} / \mathrm{ml})$ decreased TGF- $\beta_{1}$ - induced fibronectin protein levels in both CTand DD-derived fibroblasts (Fig. 7). 
a

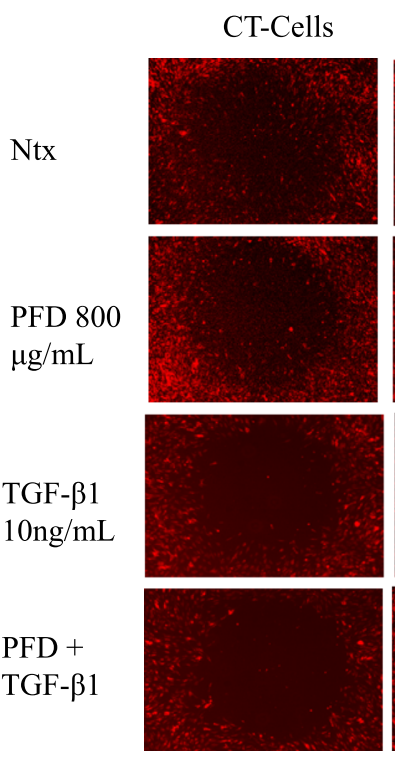

b

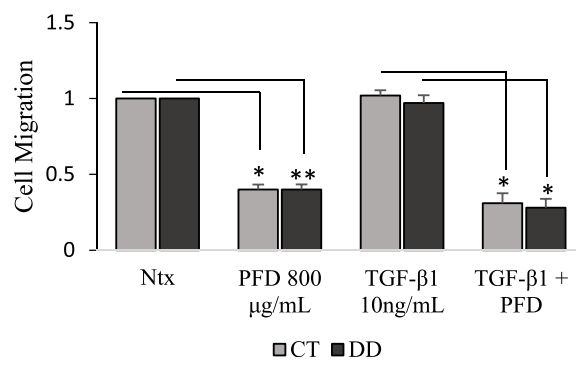

C

$3 \mathrm{D}$

DD-Cells
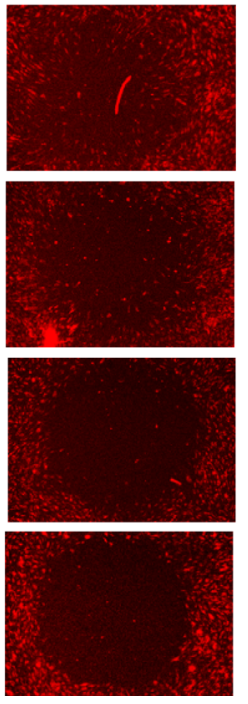

d
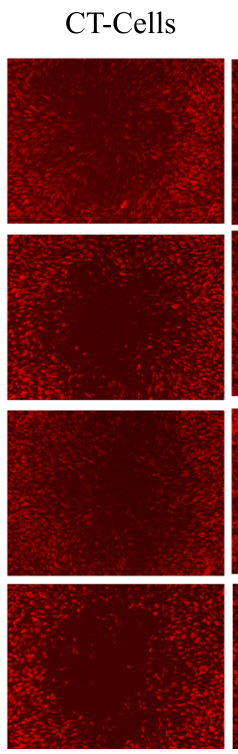

DD-Cells
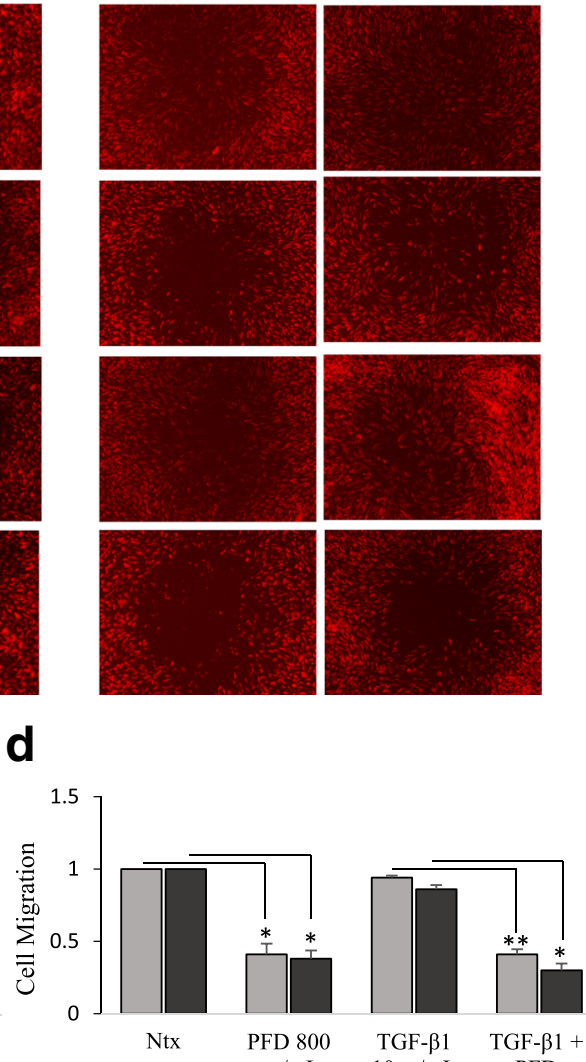

$\mu \mathrm{g} / \mathrm{mL}$

TGF- $\beta 1$

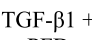

$\square \mathrm{CT} \square \mathrm{DD}$

Fig. 3 Pirfenidone suppressed basal and TGF- $\beta_{1}$ induced cell migration. $C$ - and DD-derived fibroblasts derived from three different pateint samples ( $N=3$ /group) were maintained in low-serum medium for $24 \mathrm{~h}$, then were left untreated ( $\mathrm{Ntx}$ ) or exposed to PFD ( $800 \mathrm{\mu g} / \mathrm{ml})$ in the presence or absence of TGF- $\beta_{1}(10 \mathrm{ng} / \mathrm{ml})$ to perform the 2D (a \& $\left.\mathbf{b}\right)$ and OrisTM 3D $(\mathbf{c} \& \mathbf{d})$ cell migration assays. Shown here are representative images of three different experiments from three different cultures ( $N=3$ /group) of $C T$ - and DD-derived fibroblasts done for 2D (a) and 3D (c) migration assays in triplicate. $\mathrm{NIH}$ - image analysis was used to assess the number of cells that entered the detection zones after various treatments. Data are shown as mean \pm SEM of the averages of triplicate reads for each culture derived from the three different patient samples both for $C T$ - and DD- derived fibroblasts. Statistical analysis was performed using one-way ANOVA. ${ }^{*} p<0.05 ;{ }^{* *} p<0.01,{ }^{* * *} p<0.001$

\section{PFD inhibits TGF- $\beta_{1}$-induced phosphorylation of Smad2/ Smad3}

Studies have shown that $T G F-\beta_{1}$ is a potent modulator of fibroblast and myofibroblast proliferation and differentiation [7]. All key components of the TGF- $\beta_{1} / \mathrm{Smad}$ signaling cascade were noted to have increased expression patterns in DD, resulting in accelerated TGF- $\beta_{1}$ signaling [36]. We examined the phosphorylation of Smad2/Smad3 protein as a measure for active canonical TGF- $\beta_{1}$ signaling. We detected an increase in protein levels of phospho-Smad2/3 when stimulated with TGF$\beta_{1}$ in both CT- and DD-derived fibroblasts. This increase in expression was attenuated by the addition of PFD (Fig. 8a \& b).

\section{Statistical analysis}

Statistical analyses were performed by one way ANOVA using GraphPad Prism version 7.0. Statistically significant differences between paired experimental and control groups; and paired treatments between CT cells and DD cells was performed using Dunnett's and Sidak's analyses. One sample $T$-test was used to compare the background between $\mathrm{CT}$ and $\mathrm{DD}$ cell population. A $p$ value $<0.05$ was considered significant.

\section{Discussion}

DD is a chronic, fibroproliferative disorder with high recurrence rate after all available strategies for treatment. The cellular and molecular physiology underlying this 


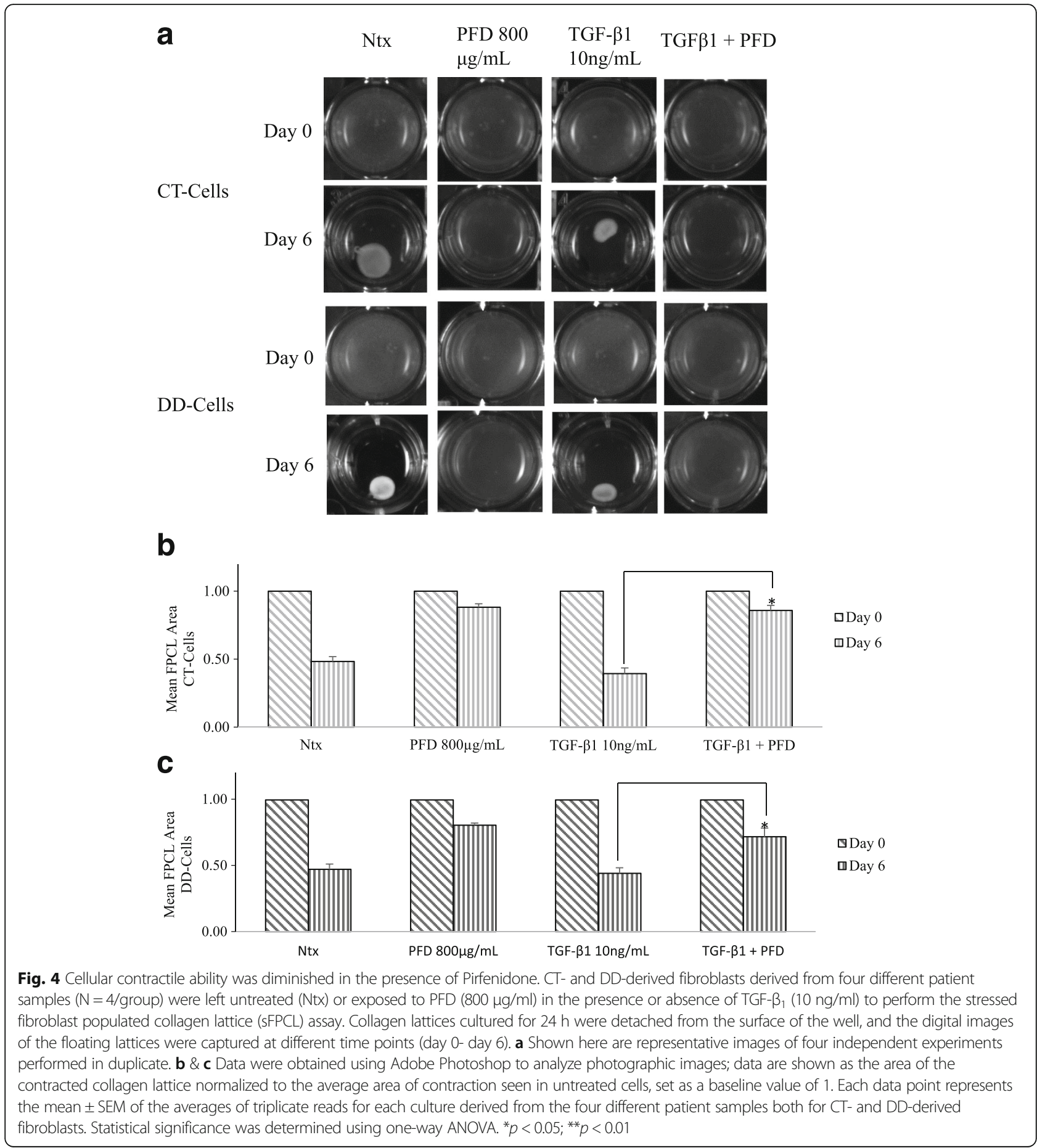

trend to recurrence remains under investigation. Our work has shown that not only fibroblasts from actively diseased cords, but also fibroblasts from phenotypically normal adjacent palmar fascia in DD have significantly altered patterns of gene expression compared to control cells from CT patients [37]. These nearby cells may therefore represent a residual manifestation of protodisease after surgery, which may be stimulated by cytokine mediators to progress to active, frank recurrence. An important such mediator, known to promote the conversion of fibroblasts to an activated myofibroblast phenotype and known to play a role in DD, is TGF- $\beta_{1}$. Accordingly, therapies that can counteract TGF- $\beta_{1}$ may also prove useful in dealing with DD.

The link between elevated TGF- $\beta_{1}$ and fibrosis is well documented but continues to grow. A recent study by 


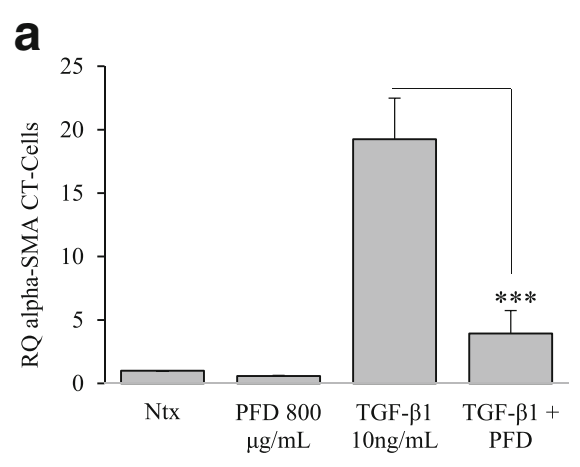

C
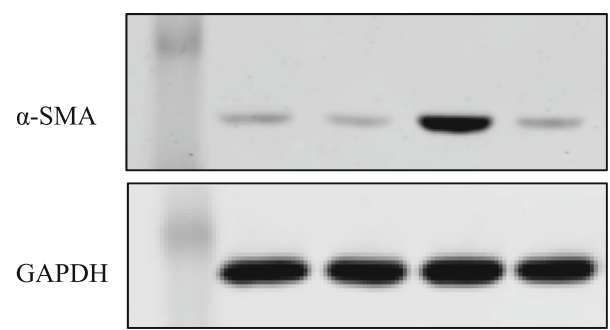

e

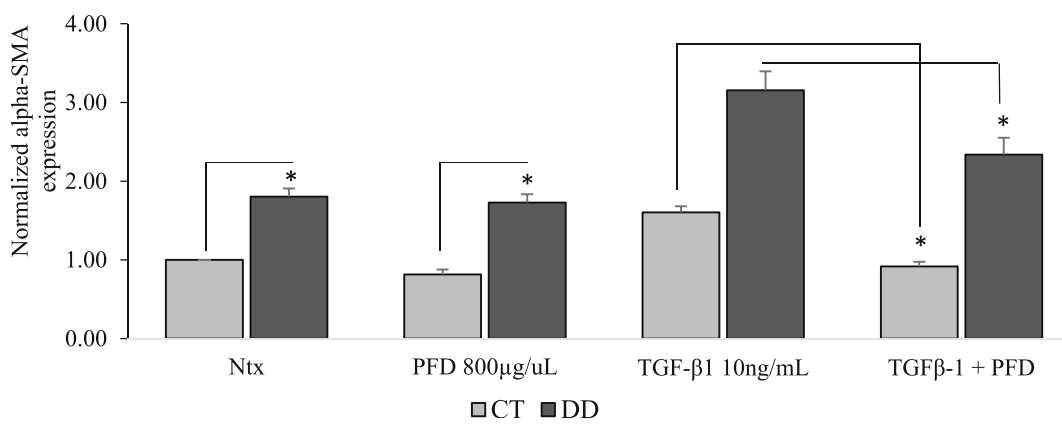

b

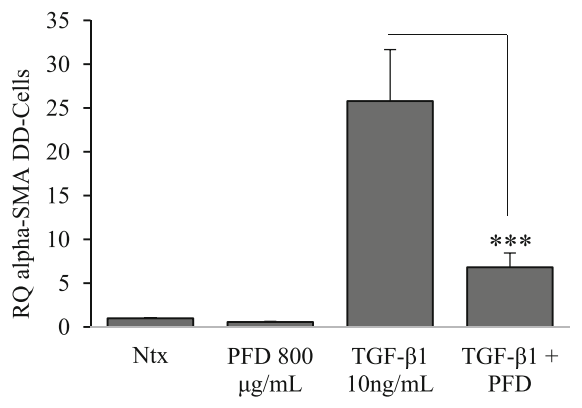

d

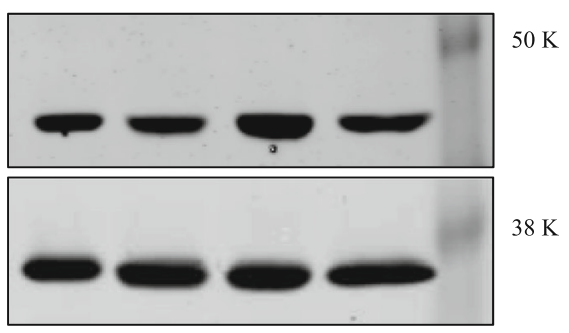

$0 \mathrm{~K}$

$\mathrm{K}$

Fig. 5 Inhibition of a-SMA levels was evident after addition of Pirfenidone. CT- and DD-derived fibroblasts derived from three different patient samples ( $N=3 /$ group) of were left untreated ( $\mathrm{Ntx}$ ) or were stimulated with PFD $(800 \mu \mathrm{g} / \mathrm{ml})$ in the presence or absence of TGF- $\beta_{1}(10 \mathrm{ng} / \mathrm{ml})$ in a-MEM medium containing $0.1 \%$ dialyzed FBS. Twenty-four hours later cell lysates were collected to determine the mRNA and protein expression of a-SMA by real-time RT-PCR ( $\mathbf{a} \& \mathbf{b}$ ) and Western blot analyses $(\mathbf{c} \& \mathbf{d})$. Real-time RT-PCR experiments were done on three independent cultures of each of the cell types. Values are mean \pm SEM of three independent studies performed in triplicate. One-way ANOVA test was used to determine the statistical significance. ${ }^{*} p<0.05,{ }^{* *} p<0.01$. Western blot analyses shown here are representative images of experiments performed using three independent primary cultures of CT- and DD-cord derived fibroblasts. Proteins obtained from different patients were processed in parallel to confirm the changes that are observed are consistent. Protein accumulation was quantified by densitometry using GAPDH as a loading control (e)

Meyer et al. [38] shows that increased circulating levels of plasma TGF $\beta_{1}$ released from platelets contribute to cardiac fibrosis that occurs in response to aortic constriction during cardiac surgery in humans. There is no study to date that correlates the presence of TGF- $\beta_{1}$ in the palmar fascial tissues with elevated levels in circulating plasma in patients suffering from DD, but neither to our knowledge has such a study been attempted. Interestingly, a case study by Cutolo et al. [39] describes a case of symmetric bilateral posterior subcapsular cataracts associated with symmetric bilateral Dupuytren's disease. In this study the authors found that the patient's serum TGF- $\beta_{1}$ concentration was almost double
$(18,290 \mathrm{pg} / \mathrm{ml})$ compared to the cataract patients that did not have Dupuytren's disease $(9961.06 \mathrm{pg} / \mathrm{ml})$. Such observations suggest that agents that will counteract TGF- $\beta_{1}$ may be useful adjuncts in the treatment of DD, especially to guard against disease recurrence.

One such agent is Pirfenidone. Multiple in vitro and in vivo studies have been performed to show the antiinflammatory and anti-fibrotic beneficial effects of PFD on cell populations derived from various tissue sources associated with fibrosis [29, 40-42]. Since PFD is already FDA-approved for use in pulmonary fibrosis, there is a substantial history of safety in human use. Our present study seeks to verify that administration of PFD can 

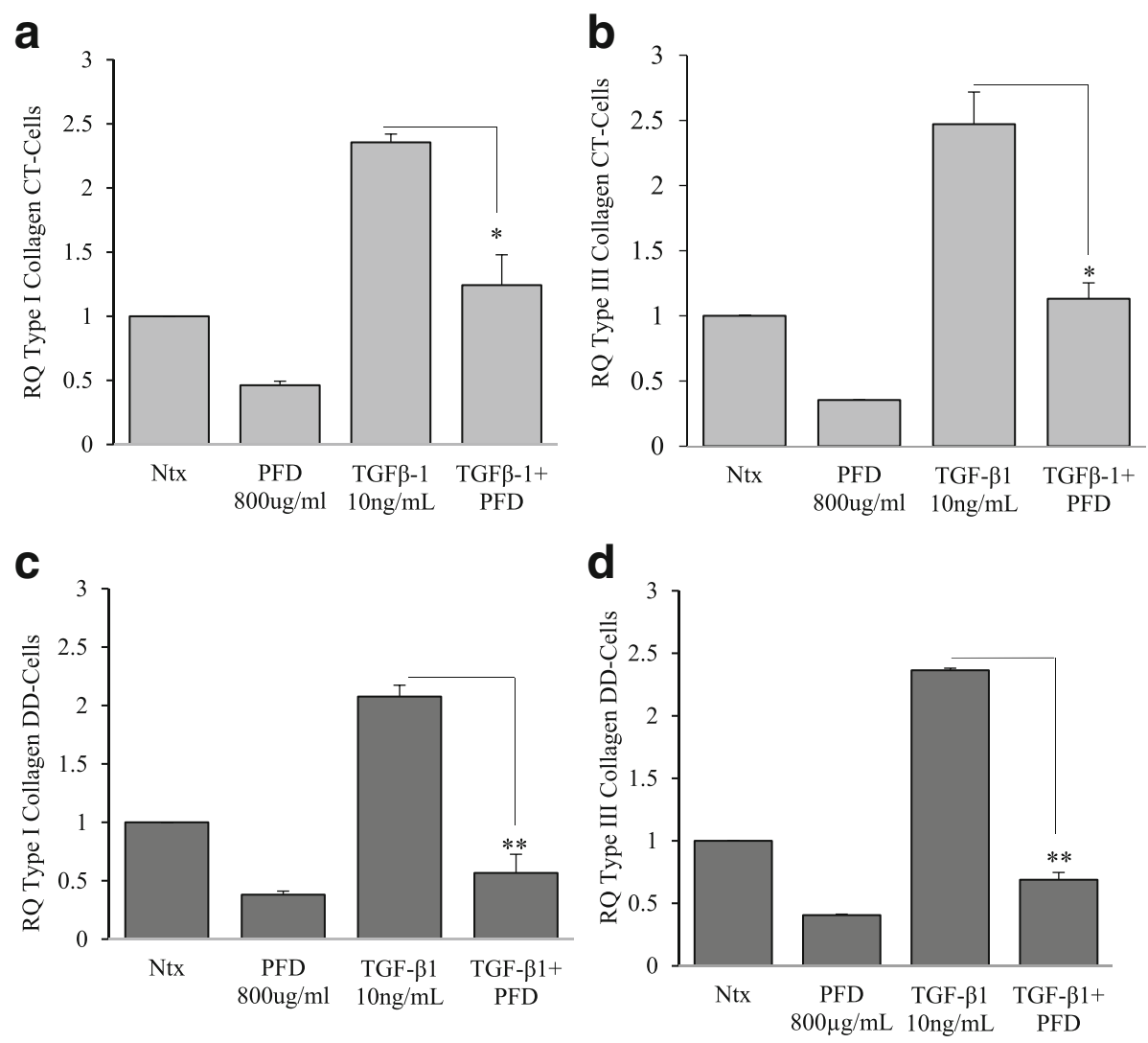

Fig. 6 Piffenidone effectively inhibited TGF- $\beta_{1}$-induction of a-2 chain of Type I and $a-1$ chain of Type III collagen. CT- and DD-derived fibroblasts derived from three independent patient samples ( $N=3$ /group) were left untreated ( $N \mathrm{tx})$ or exposed to PFD $(800 \mu \mathrm{g} / \mathrm{ml})$ in the presence or absence of TGF- $\beta_{1}$ for $24 \mathrm{~h}$. Twenty-four hours later RNA was extracted and mRNA expression levels of type I and type III collagen of CT- (a \& $\mathbf{b})$ and DD-derived fibroblasts (c \& d) were determined using real-time RT-PCR analysis. Shown is the mean \pm SEM of $n=3$ of experimental replicates from three different culture of $C T$ - and DD-fibroblasts, each performed in triplicate. ${ }^{*} p<0.05,{ }^{* *} p<0.01$

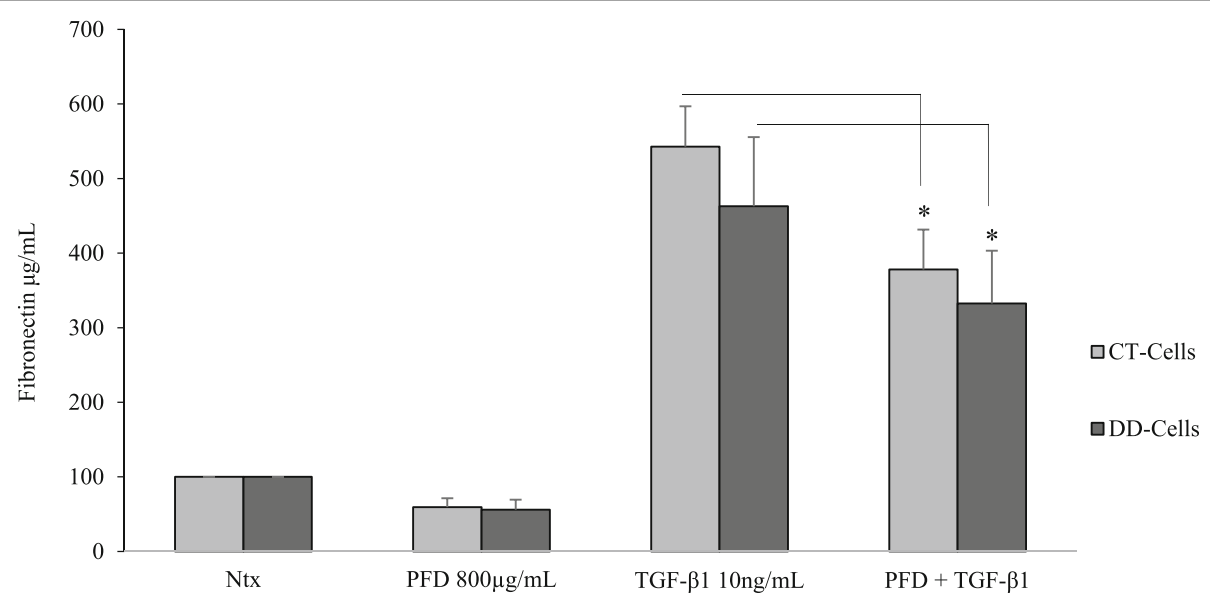

Fig. 7 Pirfenidone substantially reduced TGF- $\beta_{1}$ induction of fibronectin expression. CT- and DD-cord derived fibroblasts grown in growth medium overnight were treated with medium containing $0.1 \%$ dialyzed FBS for $24 \mathrm{~h}$. Following which, cells were treated with $800 \mu \mathrm{g} / \mathrm{mL}$ of PFD with or without $10 \mathrm{ng} / \mathrm{ml}$ TGF- $\beta_{1}$ for $24 \mathrm{~h}$. After the treatment, secreted proteins in the growth medium were collected to determine the fibronectin expression using Human Fibronectin SimpleStep ELISA Kit. CT- and DD-derived fibroblasts derived from three different patient samples ( $N=3 / g r o u p)$ were used to perform the experiment three times in triplicate. Statistical significance was determined by One-way ANOVA. ${ }^{*} p<0.05$ 


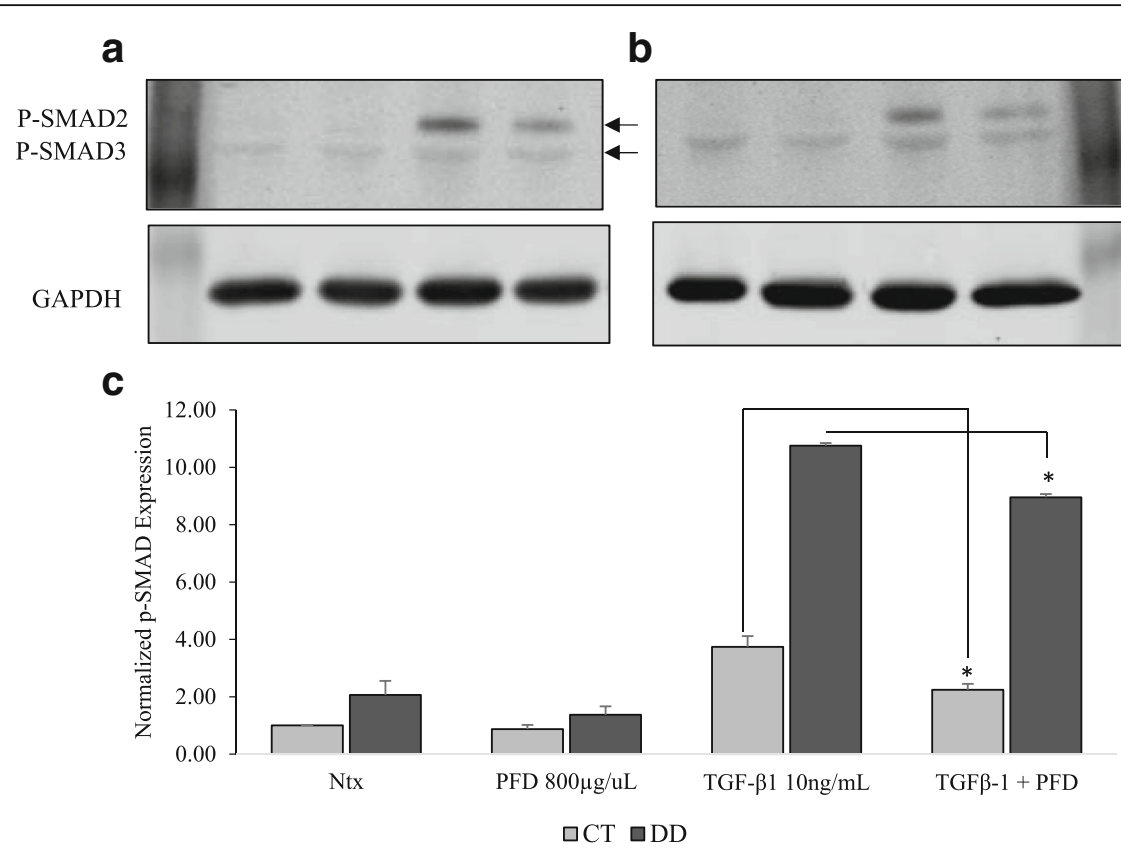

Fig. 8 Pirfenidone inhibits TGF- $\beta_{1}$-induced phosphorylation of Smad2/Smad3. CT-and DD-cord-derived fibroblasts derived from three different patient samples ( $\mathrm{N}=3$ /group) were maintained in MEM- a medium containing $0.1 \%$ dialyzed FBS for $24 \mathrm{~h}$. After $24 \mathrm{~h}$, cells were either treated or untreated with PFD $(800 \mu \mathrm{g} / \mathrm{ml})$ in the presence or absence of TGF- $\beta_{1}(10 \mathrm{ng} / \mathrm{ml})$ for additional $24 \mathrm{~h}$. Cell lysates collected from CT- $(\mathbf{a} \& \mathbf{b})$ and DD- derived fibroblasts were used to examine the expression of phosphorylated Smad2/Smad3 by Western blot analysis. Proteins obtained from different patients were processed in parallel to confirm the changes that are observed are consistent. Densitometry results are reported as the ratio of phosphorylated Smad2/Smad3 protein to GAPDH expression (c). Shown here is the representation of Western blot experiments performed using three different culture each of CT- and DD-derived fibroblasts essentially with identical results. ${ }^{*} p<0.05$

elicit similar anti-fibrotic effects against the altered physiology of Dupuytren's disease at the cellular level. We find that PFD is able to inhibit cell proliferation, migration (after TGF- $\beta_{1}$ stimulation), and contraction of DD fibroblasts, and also inhibits the expression of collagen and fibronectin, two key components of the DD ECM. A similar effect (sometimes not quite as pronounced) is seen in CT fibroblasts, as may be expected from an agent known to have broadly anti-fibrotic effects in a variety of tissue and disease circumstances. These observations indicate that PFD should be considered as a therapeutic agent against DD in a clinical trial. Others have likewise suggested the use of other antiTGF- $\beta_{1}$ medicaments such as N-acetyl-L-cysteine (NAC) and ACE inhibitors as therapeutic interventions for DD [43], but no such trial has, to our knowledge been carried out.

TGF- $\beta_{1}$ can signal via the Smad signaling pathways or by the activation of non-Smad signaling pathways including MAP kinase, Rho GTPase, and PI3 kinase-Akt, resulting in repression of epithelial marker genes and activation of mesenchymal markers [44, 45]. In order to explore the mechanisms through which TGF- $\beta_{1}$ actions are inhibited by PFD we examined the Smad-dependent pathways. Studies from other cell types indicate that PFD counteracts TGF- $\beta_{1}$ action by down-regulating phosphorylation of Smad proteins [46-49]. A previous study by Krause et al., [36] shows that DD tissues have elevated basal expression of Smad2 and Smad3, and P-Smad2 levels were found to be elevated, but not P-Smad3 levels. In our DD- derived fibroblasts in culture we did not find any such increase in the basal phosphorylation of Smad2/Smad3 compared to CT cells, but posit this may be due to the lack of stimulation by TGF- $\beta_{1}$ (whereas DD tissues in vivo may be expected to see such stimulation). When TGF- $\beta_{1}$ was added to cells, we did see significantly increased expression of P-Smad2 but not P-Smad3 in DD- derived fibroblasts, consistent with the observation in tissues. CT-derived fibroblasts also showed this increase in culture, but would not be expected to in vivo, where presumably there is little TGF- $\beta_{1}$ stimulation in CT disease. Importantly, in both cell types the increase in P-Smad2 was negated by the addition of PFD. This does suggest that, in both DD and control palmar fascial fibroblasts. PFD is acting at least partially through suppression of the canonical Smad signaling pathway.

In sum, we show that PFD has significant physiologic effects and anti-TGF- $\beta_{1}$ properties in palmar fascial fibroblasts as it does in cells from other tissue sources. Importantly, PFD is effective against actively diseased fibroblasts from DD patients, and may therefore be 
expected to have a similar potency in vivo, potentially mitigating DD disease and recurrence. It remains to be determined how best to deliver PFD to the target cell populations in the setting of DD; to date its use has largely been as a systemic (oral) medication, which may also prove useful against DD. However, gel formulations of PFD intended for topical administration have also been described. A recent clinical trial by Armendariz-Borunda et al. [27] shows that topical administration of $8 \%$ PFD gels is effective and safe in the treatment of hypertrophic scars caused by burns in children. Another recent study by Rodríguez-Castellanos et al. [50] shows that topical application of $8 \%$ PFD gels to localized scleroderma reduces both inflammation and fibrosis. These studies raise the prospect of using PFD locally in DD patients rather than via systemic oral administration. The main impediment to such a scheme may be in delivering sufficient PFD to cross the skin barrier to underlying palmar fascial tissue. However, we anticipate that doses used in this study will be achievable in vivo. Since we are aiming for topical application of PFD for use in DD patients, we expect that we can achieve the effect of the drug locoregionally with much less systemic exposure than used for treating other fibrotic conditions such as idiopathic pulmonary fibrosis (IPF). Future studies will focus on optimizing strategies to effectively deliver PFD to the palmar fascia, and to verify its ability to inhibit DD disease phenotype using a recently described orthotopic animal model of DD [31].

\section{Conclusions}

Taken together these results suggest the PFD can potentially prevent TGF- $\beta_{1}$-induced fibroblast to myofibroblast transformation and inhibit ECM production mainly Type I- and Type III- collagen and fibronectin in DD-derived fibroblasts. Further in-vivo studies with PFD may lead to a novel therapeutic application in preventing the progression or recurrence of Dupuytren's disease.

\section{Abbreviations}

ANOVA: Analysis of variance; CT: Carpal tunnel; DD: Dupuytren's disease; SFPCL: Stressed Fibroblast -Populated Collagen Lattice; TGF- $\beta_{1}$ : Transforming growth factor-beta; a - SMA: alpha smooth muscle actin

\section{Acknowledgements}

We extend our thanks to the private donor that made this study possible through his generous donation. We also thank the Department of Plastic Surgery at the University of Pittsburgh for their continuous support.

\section{Funding}

This study was supported by private donor funding and through the funding support from the Department of Plastic Surgery, University of Pittsburgh.

\section{Availability of data and materials}

All data generated are analyzed during this study are included in this published article.

\section{Authors' contributions}

LS conceived, designed the experiments, interpreted the data and drafted the manuscript. CZ planned the experiments, collected the data and interpreted the findings along with LS. FL performed the real time RT-PCR experiments. PHG was actively involved during the experimental design and planning. SK and LS discussed the experimental design. SK critically reviewed the manuscript and provided his comments. MB provided his comments on experimental design and critically reviewed the manuscript and provided comments. All authors reviewed the manuscript and provided their consent for publication.

\section{Competing interests}

The authors declare that they have no competing interests.

\section{Consent for publication}

Not applicable.

\section{Ethics approval and consent to participate}

DD cord and CT fascial tissue samples were surgically resected at the Division of Upper Extremity Surgery, Department of Orthopaedic Surgery, Allegheny General Hospital, Pittsburgh, PA. All subjects signed the written informed consent forms, and the protocol was approved by the Allegheny-Singer Research Institute's Institutional Review Board (IRB protocol no. RC-4040). The study protocol strictly conformed to the ethical guidelines of the 1975 Declaration of Helsinki.

\section{Author details}

${ }^{1}$ Department of Plastic Surgery, University of Pittsburgh, Pittsburgh, PA 15261, USA. ²Department of Orthopaedic Surgery, University of Pittsburgh, Pittsburgh, PA 15261, USA. 'McGowan Institute for Regenerative Medicine, University of Pittsburgh, Pittsburgh, PA, USA. ${ }^{4}$ Department of Plastic Surgery, University of Pittsburgh, 3550 Terrace Street, Scaife Hall, S685.2, Pittsburgh, PA 15261, USA.

Received: 22 June 2016 Accepted: 3 November 2016

Published online: 11 November 2016

\section{References}

1. Rayan GM. Dupuytren disease: anatomy, pathology, presentation, and treatment. J Bone Joint Surg Am. 2007:89:189-98.

2. Shih B, Bayat A. Scientific understanding and clinical management of Dupuytren disease. Nat Rev Rheumatol. 2010;6:715-26.

3. Michou L, Lermusiaux JL, Teyssedou JP, Bardin T, Beaudreuil J, et al. Genetics of Dupuytren's disease. Joint Bone Spine. 2012;79:7-12.

4. Arkkila PE, Kantola IM, Viikari JS. Dupuytren's disease: association with chronic diabetic complications. J Rheumatol. 1997;24(1):153-9.

5. Mikkelsen OA. Dupuytren's disease-initial symptoms, age of onset and spontaneous course. Hand. 1977;9:11-5

6. Tomasek JJ, Vaughan MB, Haaksma CJ. Cellular structure and biology of Dupuytren's disease. Hand Clin. 1999;15:21-34

7. Tomasek JJ, Gabbiani G, Hinz B, et al. Myofibroblasts and mechano-regulation of connective tissue remodeling. Nat Rev Mol Cell Biol. 2002;3:349-63.

8. Shaw RB, Chong AK, Zhang A, et al. Dupuytren's disease: history, diagnosis, and treatment. Plast Reconstr Surg. 2007;120:44e-54.

9. Lanting R, Broekstra DC, Werker PM, van den Heuvel ER. A systematic review and meta-analysis on the prevalence of Dupuytren disease in the general population of Western countries. Plast Reconstr Surg. 2014;133:593-603.

10. Dibenedetti DB, Nguyen D, Zografos L, Ziemiecki R, Zhou X. Prevalence, incidence, and treatments of Dupuytren's disease in the United States: Results from a population-based study. Hand (NY). 2011;6:149-58.

11. Macaulay D, Ivanova J, Birnbaum H, Sorg R, Skodny P. Direct and indirect costs associated with Dupuytren's contracture. J Med Econ. 2012;15:664-71.

12. van Rijssen $A L$, ter Linden $H$, Werker PM. Five-year results of a randomized clinical trial on treatment in Dupuytren's disease: percutaneous needle fasciotomy versus limited fasciectomy. Plast Reconstr Surg. 2012;129:469-77.

13. Hurst LC, Badalamente MA, Hentz VR, Hotchkiss RN, Kaplan FT, Meals RA, Smith TM, Rodzvilla J. CORD I Study Group. Injectable collagenase clostridium for Dupuytren's contracture. N Engl J Med. 2009;361:968-79.

14. Rozen WM, Edirisinghe Y, Crock J. Late complications of clinical clostridium histolyticum collagenase use in Dupuytren's disease. PLoS ONE. 2012;7(8):e43406.

15. Povlsen B, Singh S. Acute double flexor tendon ruptures following injection of collagenase clostridium histolyticum (Xiapex) for Dupuytren's contracture. BMJ Case Rep. 2014

16. Worrell M. Dupuytren's disease. Orthopedics. 2012;35:52-60. 
17. Badalamente MA, Sampson SP, Hurst LC, Dowd A, Miyasaka K. The role of transforming growth factor beta in Dupuytren's disease. J Hand Surg [Am]. 1996;21(2):210-5.

18. Vaughan MB, Howard EW, Tomasek JJ. Transforming growth factor- $\beta 1$ promotes the morphological and functional differentiation of the myofibroblast. Exp Cell Res. 2000;257:180-9.

19. Satish L, Gallo PH, Baratz ME, Johnson S, Kathju S. Reversal of TGF- $\beta_{1}$ stimulation of a-smooth muscle actin and extracellular matrix components by cyclic AMP in Dupuytren's-derived fibroblasts. BMC Musculoskelet Disord. 2011;12:113.

20. Swaney JS, Roth DM, Olson ER, Naugle JE, Meszaros GJ, Insel PA Inhibition of cardiac myofibroblast formation and collagen synthesis by activation and overexpression of adenylyl cyclase. Proc Natl Acad Sci. 2005;102:437-42.

21. Liu X, Ostrom RS, Insel PA. CAMP-elevating agents and adenylyl cyclase overexpression promote an antifibrotic phenotype in pulmonary fibroblasts. Am J Physiol. 2004;286:C1089-99.

22. Kavitha C, Rajamani K, Vadivel E. Coleus forskohlii- A comprehensive review on morphology, phytochemistry and pharmacological aspects. J Med Plants Res. 2010;4:278-85.

23. Noble PW, Albera C, Bradford WZ, et al. Pirfenidone in patients with idiopathic pulmonary fibrosis (CAPACITY): two randomised trials. Lancet. 2011:377:1760-9.

24. Al-Bayati MA, Xie Y, Mohr FC, et al. Effect of pirfenidone against vanadateinduced kidney fibrosis in rats. Biochem Pharmacol. 2002;64:517-25.

25. Lee KW, Everett TH, Rahmutula D, et al. Pirfenidone prevents the development of a vulnerable substrate for atrial fibrillation in a canine model of heart failure. Circulation. 2006:114:1703-12.

26. Di Sario A, Bendia E, Macarri G, et al. The anti-fibrotic effect of pirfenidone in rat liver fibrosis is mediated by downregulation of procollagen alpha1 (I), TIMP-1 and MMP-2. Dig Liver Dis. 2004;36:744-51.

27. Armendariz-Borunda J, Lyra-Gonzalez I, Medina-Preciado D, et al. A controlled clinical trial with pirfenidone in the treatment of pathological skin scarring caused by burns in pediatric patients. Ann Plast Surg. 2012;68:22-8.

28. Lasky J. Pirfenidone. IDrugs. 2004;7(2):166-72.

29. Hewitson TD, Kelynack KJ, Tait MG, et al. Pirfenidone reduces in vitro rat renal fibroblast activation and mitogenesis. J Nephrol. 2001;14(6):453-60.

30. Thannickal YJ, Flaherty KR, Martinez FJ, Lynch JP. iii: Idiopathic pulmonary fibrosis: emerging concepts on pharmacotherapy. Expert Opin Pharmacother. 2004:5(8):1671-86.

31. Satish L, Palmer B, Liu F, Papatheodorou L, Rigatti L, Baratz ME, Kathju S. Developling an animal model of Dupuytren's diseaseby orthotopic transplantation of human fibroblasts into athymic rat. BMC Musculoskelt Disord. 2015;16:138.

32. Satish L, O'Gorman DB, Johnson S, Raykha C, Gan BS, Wang JH, Kathju S. Increased CCT-eta expression is a marker of latent and active disease and a modulator of fibroblast contractility in Dupuytren's contracture. Cell Stress Chaperones. 2013;18:397-404.

33. Brickley-Parsons D, Glimcher MJ, Smith RJ, Albin R, Adams JP. Biochemical changes in the collagen of the palmar fascia in patients with Dupuytren's disease. J Bone Joint Surg Am. 1981;63(5):787-97.

34. Howard JC, Varallo VM, Ross DC, Faber KJ, Roth JH, Seney S, Gan BS. Wound healing-associated proteins $\mathrm{Hsp47}$ and fibronectin are elevated in Dupuytren's contracture. J Surg Res. 2004;117:232-8.

35. Vi L, Feng L, Zhu RD, Wu Y, Satish L, Gan BS, O'Gorman DB. Periostin differentially induces proliferation, contraction and apoptosis of primary Dupuytren's disease and adjacent palmar fascia cells. Exp Cell Res. 2009:315:3574-86.

36. Krause $C$, Kloen P, Dijke PT. Elevated transforming growth factor $\beta$ and mitogen-activated protein kinase pathways mediate fibrotic traits of Dupuytren's disease fibroblasts. Fibrogenesis Tissue Repair. 2011;4:14

37. Satish L, LaFramboise WA, Johnson S, Vi L, Njarlangattil A, Raykha C, KrillBurger JM, Gallo PH, O'Gorman DB, Gan BS, Baratz ME, Ehrlich GD, Kathju S. Fibroblasts from phenotypically normal palmar fascia exhibit molecular profiles highly similar to fibroblasts from active disease in Dupuytren's Contracture. BMC Med Genomics. 2012;5:15

38. Meyer A, Wang W, Qu J, Croft L, Degen JL, Coller BS, Ahamed J. Platelet TGF- $\beta$ contributions to plasma TGF- $\beta_{1}$, cardiac fibrosis, and systolic dysfunction in a mouse model of pressure overload. Blood. 2012;119:1064-74

39. Cutolo CA, Lombardo S, Verticchio Vercellin AC, Bertonr C, De Amici M, Antoniazzi E, Milano G. Cataracts and Dupuytren disease: a case report and review of the literature. Eur J Opthalmol. 2013;23(1):135-7.
40. Shi Q, Liu X, Bai Y, Cui C, Li J, Li Y, Hu S, Wei Y. In vitro effects of pirfenidone on cardiac fibroblasts: proliferation, myofibroblast differentiation, migration and cytokine secretion. PLOS ONE. 2011;6:Article e28134.

41. Lin $X, Y u M$, Wu K, Yuan $H$, Zhong $H$. Effects of pirfenidone on proliferation, migration, and collagen contraction of human Tenon's fibroblasts in vitro Invest. Ophthalmol Vis Sci. 2009;50:3763-70.

42. Xiang XH, Jiang TP, Zhang S, Song J, Li X, Yang JY, Zhou S. Pirfenidone inhibits proliferation, arrests the cell cycle, and downregulates heat shock protein-47 and collagen type I in rat hepatic stellate cells in vitro. Mol Med Rep. 2015;12:309-14.

43. Knobloch K, Redeker J, Vogt PM. Antifibrotic medication using a combination of $\mathrm{N}$-acetyl-L-cystein (NAC) and ACE inhibitors can prevent the recurrence of Dupuytren's disease. Med Hypotheses. 2009;73(5):659-61.

44. Derynck R, Zhang YE. Smad-dependent and Smad-independent pathways in TGF-beta family signalling. Nature. 2003:425(6958):577-84.

45. Xu J, Lamouille S, Derynck R. TGF-beta-induced epithelial to mesenchymal transition. Cell Res. 2009:19:156-72.

46. Yuan Q, Wang L, Zhang F, Wang R, Fu X, Peng Z, Ning W, Hu G, Wang Z, Tao L. Fluorofenidone suppresses epithelial-mesenchymal transition and the expression of connective tissue growth factor via inhibiting TGF-beta/Smads signaling in human proximal tubular epithelial cells. Pharmazie. 2011;66(12):961-7.

47. Yang $Y, Y e ~ Y, L i n X$, Wu K, Yu M. Inhibition of pirfenidone on TGF-beta2 induced proliferation, migration and epithelial-mesenchymal transition of human lens epithelial cells line SRA01/04. PLoS ONE. 2013;8(2):e56837.

48. Choi K, Lee K, Ryu SW, Im M, Kook KH, Choi C. Pirfenidone inhibits transforming growth factor- $\beta 1$-induced fibrogenesis by blocking nuclear translocation of Smads in human retinal pigment epithelial cell line ARPE-19. Mol Vis. 2012;18:1010-20

49. Wang J, Yang Y, Xu J, Lin X, Wu K, Yu M. Pirfenidone inhibits migration, differentiation, and proliferation of human retinal pigment epithelial cells in vitro. Mol Vis. 2013;19:2626-35.

50. Rodríguez-Castellanos M, Tlacuilo-Parra A, Sánchez-Enríquez S, Vélez-Gómez E, Guevera-Gutiérrez E. Pirfenidone gel in patients with localized scleroderma: a phase II study. Arthritis Res Ther. 2015;16(6):510.

\section{Submit your next manuscript to BioMed Central and we will help you at every step:}

- We accept pre-submission inquiries

- Our selector tool helps you to find the most relevant journal

- We provide round the clock customer support

- Convenient online submission

- Thorough peer review

- Inclusion in PubMed and all major indexing services

- Maximum visibility for your research

Submit your manuscript at www.biomedcentral.com/submit
) Biomed Central 